\title{
Composition dependence of physical and optical properties in Ge-As-S chalcogenide glasses
}

Yan Yang ${ }^{\text {a }}$, Zhiyong Yang ${ }^{\text {a,* }}$, Pierre Lucas ${ }^{\text {b,* }}$, Yuwei Wang ${ }^{\text {a }}$, Zhijie Yang ${ }^{\text {a }}$, Anping Yang ${ }^{\mathrm{a}}$, Bin Zhang ${ }^{\mathrm{a}}$, Haizheng Tao ${ }^{\mathrm{c}}$

${ }^{a}$ Jiangsu Key Laboratory of Advanced Laser Materials and Devices, School of Physics and Electronic Engineering, Jiangsu Normal University, Xuzhou, Jiangsu 221116, China

${ }^{\mathrm{b}}$ Department of Materials Science and Engineering, University of Arizona, Tucson, Arizona 85712

${ }^{\mathrm{c}}$ State Key Laboratory of Silicate Materials for Architectures, Wuhan University of Technology, Wuhan, Hubei 430070, China

\begin{abstract}
The composition dependence of density $(d)$, refractive index $(n)$ and optical bandgap $\left(E_{g}\right)$ of Ge-As-S chalcogenide glasses is investigated. It is shown that $d$ correlates linearly with sulfur content but relatively poorly with the mean coordination number (MCN). It is also shown that $n$ does not correlate directly with $d$, and instead a semi-empirical relation based on the molar refractivity $(R)$ of $\mathrm{Ge}$, As and $\mathrm{S}$ is derived, permitting to predict $n$ from $d$ with less than $1 \%$ error. A convenient method based on diffuse reflectance is proposed to measure $E_{g}$ of Ge-As-S glasses with good accuracy. It is shown that the value of $E_{g}$ is dominated by the $\mathrm{S}$ content. These findings make it convenient to tailor the physical and optical properties of glasses in Ge-As-S system.
\end{abstract}

Keywords: Chalcogenide glasses; Refractive index; Optical bandgap; Diffuse

\footnotetext{
*Corresponding authors: yangzhiyong@jsnu.edu.cn; pierre@email.arizona.edu.
} 
reflectance spectrum

\section{Introduction}

Chalcogenide glasses (ChG) are increasingly popular infrared (IR) optical materials because of their wide IR transparency windows, superior thermal and chemical stability, and low costs. Currently, IR lenses made of ChG are manufactured for thermal imaging systems $[1,2]$ while chalcogenide fibers and planar waveguides are produced for IR light transmission [3,4], optical sensing [5-7], and nonlinear optics [8-10]. Among the physical parameters of $\mathrm{ChG}$, the refractive index $(n)$ may be the most important one as it is crucial for most optical designs. However, limited attention has been paid to the origin and control of this parameter in ChG. In this paper the composition dependence of $n$, optical bandgap $\left(E_{g}\right)$ and density $(d)$ in Ge-As-S ChG is investigated. We examine the co-dependence between the three parameters as well as the mean coordination number (MCN). MCN defines the average number of covalent bond per atoms, and is calculated by the sum of respective elemental concentration times their covalent coordination number [11]. A semi-empirical relation is proposed to predict $n$ from $d$ and a method based on diffuse reflectance is described to measure $E_{g}$. The Ge-As-S system was chosen for this investigation because it has a large glass forming domain, so that a large number of compositions with remarkably different structures and properties can be tested. In addition, Ge-As-S glasses are also expected to be relatively robust materials for nonlinear optics and IR gratings due to their superior mechanical property, relatively high power damage threshold, and tunable photosensitivity [12-14].

\section{Experimental procedures}

Ge-As-S glasses were synthesized by the melt-quenching technique [10]. High-purity Ge $(5 \mathrm{~N})$, As $(6 \mathrm{~N})$ and $\mathrm{S}(6 \mathrm{~N})$ elements were weighed in a glove box filled 
with dry $\mathrm{N}_{2}$, and loaded into a low-OH silica tube with an inner diameter of $15 \mathrm{~mm}$. Before weighing, the arsenic was thermally treated under vacuum $\left(<10^{-5}\right.$ torr $)$ for $1 \mathrm{~h}$ to remove surface oxide impurities, and the sulfur was sublimated under vacuum to eliminate most carbon and hydrogen related impurities. The tube containing the raw materials was then evacuated $\left(<10^{-5}\right.$ torr) and flame-sealed. After that, the mixture was homogenized at $800-850^{\circ} \mathrm{C}$ for more than $12 \mathrm{~h}$ in a rocking furnace. In the end, the tube containing the melt was quenched in water and the formed glass was annealed near its glass transition temperature for 3 hours.

The amorphous nature of the samples was verified by X-ray diffraction (XRD) measurements (D2 Phaser, Bruker Corporation, Karlsruhe, Germany). The sample compositions were confirmed (within the experimental uncertainty of $\pm 1 \mathrm{~mol} \%$ ) using the energy-dispersive X-ray spectroscopy (EDS) feature of a scanning electron microscope (JSM-6510, JEOL, Tokyo, Japan). The $d$ of the glasses were measured using the Archimede's method. A balance with an accuracy of $0.0001 \mathrm{~g}$ was used. Each sample was measured 6 times, and the error of measured $d$ was about $\pm 0.01 \mathrm{~g} / \mathrm{cm}^{3}$. The $\mathrm{E}_{\mathrm{g}}$ of the glasses were determined from their diffuse reflectance spectra (DRS), which were recorded on fine glass powders using a spectrophotometer (Lambda 950, Perkin-Elmer, Waltham, MA) equipped with a $\mathrm{PbS}$ integrating sphere. The ground glass powders were put onto standard sieves with different meshes. The powders passing through the meshes were used for the measurement. Each glass was measured 5 times, and the error of determined $\mathrm{E}_{\mathrm{g}}$ was about $\pm 0.01 \mathrm{eV}$. The $n$ of the glasses in the $1.7-20 \mu \mathrm{m}$ range were measured on single-side polished glass discs $(\varnothing 15 \mathrm{~mm})$ by an IR variable angle spectroscopic ellipsometer (IR-VASE, J. A. Woollam, Lincoln, NE). The Ge-As-S glasses have Brewster's angles of about $64-66.5^{\circ}$. To avoid sudden changes of the phase shift in the reflected lights, the angles of incidence were selected 
outside of this range. In these measurements, they were selected at $70^{\circ}$ and $77^{\circ}$. The spectral resolution was $16 \mathrm{~cm}^{-1}$. Sellmeier equations, which are commonly used to show dispersion of $n$ in chalcogenide glasses [7, 15], were used to fit the data. Each sample was measured more than 3 times, and the error of measured $n$ was about \pm 0.001 . All measurements were conducted at room temperature.

\section{Results}

In order to systematically investigate composition dependence of $n, d$ and $E_{g}$ in Ge-As-S glass system, four groups of glasses with distinctive features were prepared: (i) $\mathrm{Ge}_{0.1} \mathrm{As}_{\mathrm{x}} \mathrm{S}_{0.9-\mathrm{x}}, \mathrm{x}=0.1,0.2,0.28$ and 0.35; (ii) $\mathrm{Ge}_{\mathrm{x}} \mathrm{As}_{0.1} \mathrm{~S}_{0.9-\mathrm{x}}, \mathrm{x}=0.05,0.1,0.15,0.2$, $0.25,0.3$ and 0.35; (iii) $\mathrm{Ge}_{\mathrm{x}} \mathrm{As}_{0.2} \mathrm{~S}_{0.8-\mathrm{x}}, \mathrm{x}=0.1,0.15,0.2,0.25$, and 0.3; and (iv) $\mathrm{Ge}_{\mathrm{x}} \mathrm{As}_{\mathrm{x}} \mathrm{S}_{1-2 \mathrm{x}}, \mathrm{x}=0.1,0.15,0.182,0.2$ and 0.25 . These compositions cover a quite large part of the glass forming domain (see Fig.1) [16] and therefore are good representatives in this glass system. Table 1 lists the values of $n, d$ and $E_{g}$ of the Ge-As-S glasses. The $n$ of the $\mathrm{Ge}_{0.1} \mathrm{As}_{0.35} \mathrm{~S}_{0.55}$ glass was not measured because it had inferior thermal stability and was difficult to form a homogeneous glass with a diameter large enough for the measurement. The $d$ follows a remarkably linear dependence on S content regardless of the Ge/As ratio (see Fig.2a). This is consistent with the lower molar mass of $\mathrm{S}$ in comparison to Ge and As. While $d$ broadly increase with increasing $M C N$ the correlation is relatively poor (see Fig.2b). For example, $\mathrm{Ge}_{0.1} \mathrm{As}_{0.2} \mathrm{~S}_{0.7}$ glass $(\mathrm{MCN}=2.4)$ has higher $d$ than $\mathrm{Ge}_{0.2} \mathrm{As}_{0.1} \mathrm{~S}_{0.7}$ glass ( $\left.\mathrm{MCN}=2.5\right)$; and $\mathrm{Ge}_{0.25} \mathrm{As}_{0.1} \mathrm{~S}_{0.65}$ glass $(\mathrm{MCN}=2.6)$ shows lower $d$ than $\mathrm{Ge}_{0.1} \mathrm{As}_{0.28} \mathrm{~S}_{0.62}$ glass (MCN=2.48). Similarly $n$ broadly increases with increasing $d$ as would be expected from the concomitant increase in electronic density but the correlation is poor as shown in Fig. 2c. No apparent correlation is found between the $n$ and $M C N$. 


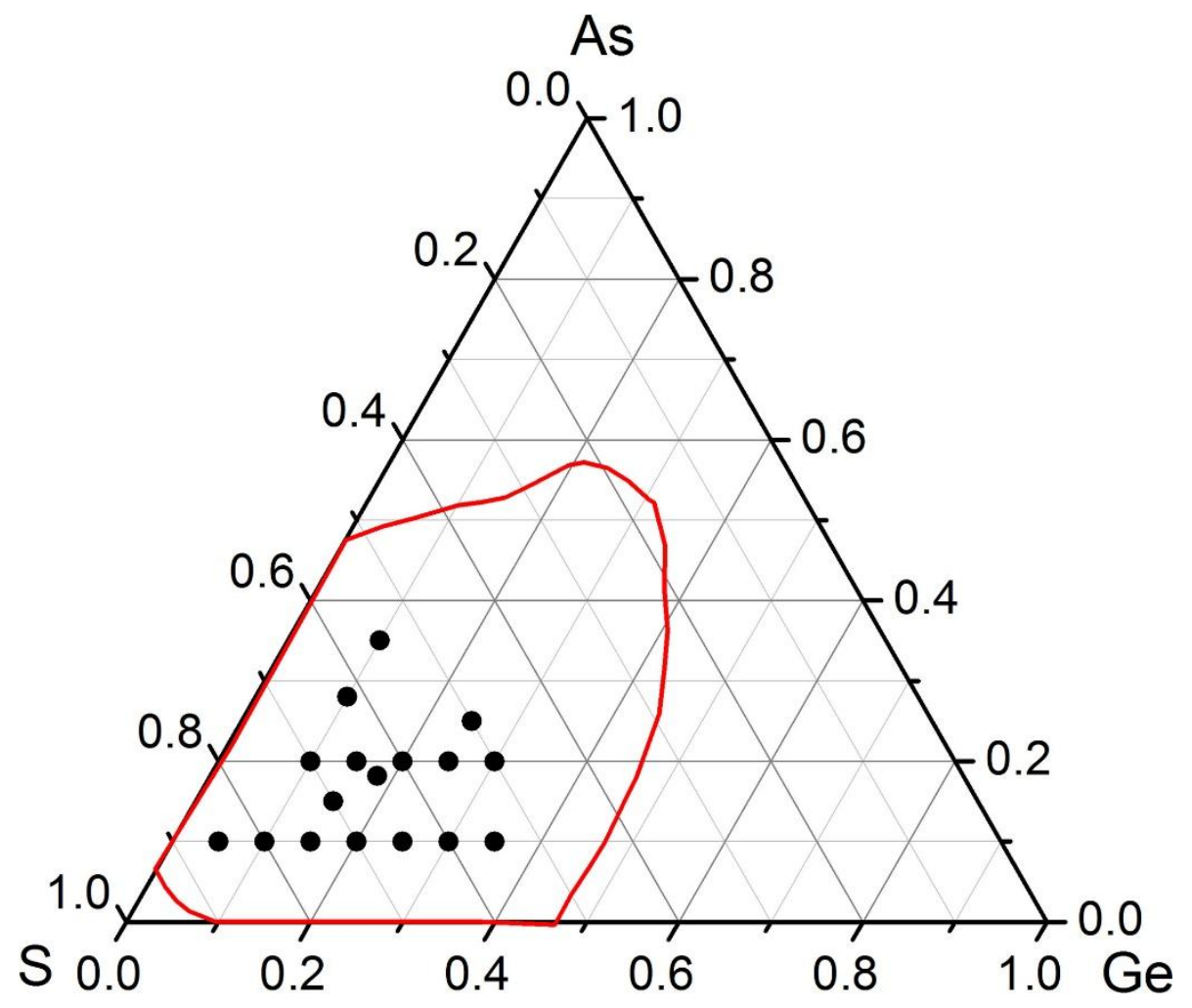

Fig.1 Glass forming domain of Ge-As-S system and 17 compositions synthesized in this study 
Table 1. Mean coordination numbers $(M C N)$, densities $(d)$, optical bandgaps $\left(E_{g}\right)$, measured $\left(n_{\text {mea }}\right)$ and calculated $\left(n_{\text {cal }}\right)$ refractive indices at $6 \mu \mathrm{m}$, and the deviations of $n_{\text {cal }}$ from $n_{\text {mea }}$ for Ge-As-S glasses.

\begin{tabular}{|c|c|c|c|c|c|c|}
\hline Composition & $\mathrm{MCN}$ & $\begin{array}{c}d \\
\left( \pm 0.01 \mathrm{~g} / \mathrm{cm}^{3}\right)\end{array}$ & $\begin{array}{c}E_{g} \\
( \pm 0.01 \mathrm{eV})\end{array}$ & $\begin{array}{c}n_{m e a} \\
( \pm 0.001)\end{array}$ & $n_{c a l}$ & $\begin{array}{c}\text { Deviation } \\
(\%)\end{array}$ \\
\hline $\mathrm{Ge}_{0.1} \mathrm{As}_{0.1} \mathrm{~S}_{0.8}$ & 2.3 & 2.52 & 2.72 & 2.087 & 2.082 & -0.24 \\
\hline $\mathrm{Ge}_{0.1} \mathrm{As}_{0.2} \mathrm{~S}_{0.7}$ & 2.4 & 2.82 & 2.57 & 2.195 & 2.188 & -0.32 \\
\hline $\mathrm{Ge}_{0.1} \mathrm{As}_{0.28} \mathrm{~S}_{0.62}$ & 2.48 & 3.07 & 2.47 & 2.279 & 2.283 & 0.18 \\
\hline $\mathrm{Ge}_{0.1} \mathrm{As}_{0.35} \mathrm{~S}_{0.55}$ & 2.55 & 3.15 & 2.46 & - & - & - \\
\hline $\mathrm{Ge}_{0.05} \mathrm{As}_{0.1} \mathrm{~S}_{0.85}$ & 2.2 & 2.37 & 2.72 & 2.059 & 2.044 & -0.73 \\
\hline $\mathrm{Ge}_{0.15} \mathrm{As}_{0.1} \mathrm{~S}_{0.75}$ & 2.4 & 2.65 & 2.70 & 2.099 & 2.107 & 0.381 \\
\hline $\mathrm{Ge}_{0.2} \mathrm{As}_{0.1} \mathrm{~S}_{0.7}$ & 2.5 & 2.79 & 2.71 & 2.130 & 2.139 & 0.42 \\
\hline $\mathrm{Ge}_{0.25} \mathrm{As}_{0.1} \mathrm{~S}_{0.65}$ & 2.6 & 2.89 & 2.79 & 2.129 & 2.145 & 0.75 \\
\hline $\mathrm{Ge}_{0.3} \mathrm{As}_{0.1} \mathrm{~S}_{0.6}$ & 2.7 & 2.99 & 2.50 & 2.155 & 2.153 & -0.09 \\
\hline $\mathrm{Ge}_{0.35} \mathrm{As}_{0.1} \mathrm{~S}_{0.55}$ & 2.8 & 3.20 & 2.37 & 2.239 & 2.231 & -0.36 \\
\hline $\mathrm{Ge}_{0.15} \mathrm{As}_{0.2} \mathrm{~S}_{0.65}$ & 2.5 & 2.96 & 2.61 & 2.217 & 2.220 & 0.14 \\
\hline $\mathrm{Ge}_{0.25} \mathrm{As}_{0.2} \mathrm{~S}_{0.55}$ & 2.7 & 3.14 & 2.35 & 2.220 & 2.221 & 0.05 \\
\hline $\mathrm{Ge}_{0.3} \mathrm{As}_{0.2} \mathrm{~S}_{0.5}$ & 2.8 & 3.32 & 2.23 & 2.307 & 2.284 & -0.99 \\
\hline $\mathrm{Ge}_{0.15} \mathrm{As}_{0.15} \mathrm{~S}_{0.7}$ & 2.45 & 2.81 & 2.65 & 2.163 & 2.166 & 0.14 \\
\hline $\mathrm{Ge}_{0.182} \mathrm{As}_{0.182} \mathrm{~S}_{0.636}$ & 2.546 & 2.97 & 2.61 & 2.197 & 2.204 & 0.32 \\
\hline $\mathrm{Ge}_{0.2} \mathrm{As}_{0.2} \mathrm{~S}_{0.6}$ & 2.6 & 2.99 & 2.54 & 2.164 & 2.180 & 0.74 \\
\hline $\mathrm{Ge}_{0.25} \mathrm{As}_{0.25} \mathrm{~S}_{0.5}$ & 2.75 & 3.32 & 2.12 & 2.298 & 2.298 & 0 \\
\hline
\end{tabular}



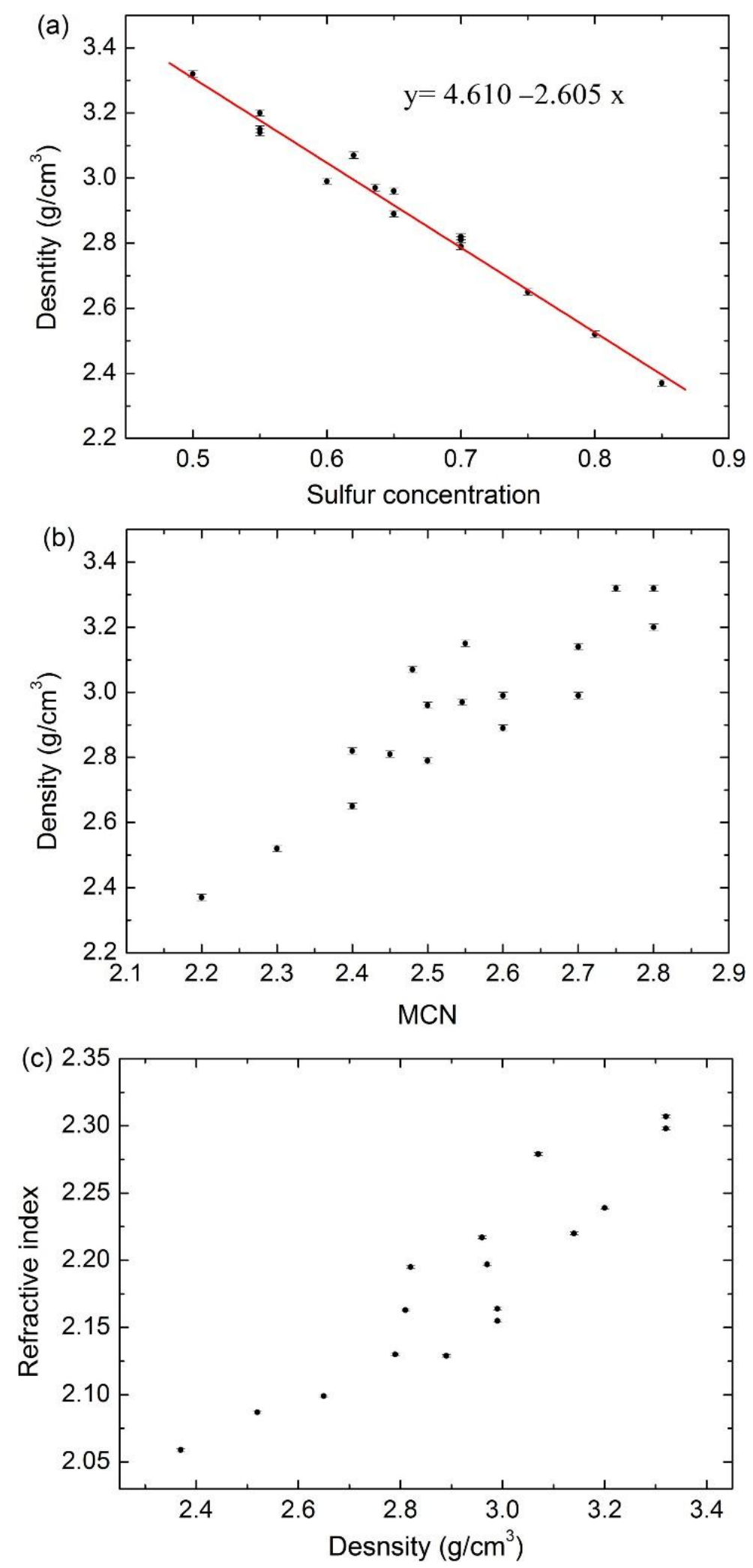

Fig.2. Correlations between parameters of Ge-As-S glasses: (a) A linear plot of density vs S concentration; (b) the variation of density with $\mathrm{MCN}$; (c) the variation of refractive index with density. 


\section{Discussion}

\subsection{Refractive index and density}

The correlation between $d$ and $n$ is indeed more complex and must account for the molar refractivity of the sample. The $n$ of a glass mainly depends on the electric polarizability $(p)$ of constituent elements and the glass density $(d)$ [17]. The $p$ represents the relative tendency of the electron cloud of an atom to be distorted from its normal shape by an external electric field. A glass consisting of atoms with larger radius, which are more likely to be polarized, tends to exhibit a higher $n$. The $n$ of a glass could be estimated from the $p$ and $d$ using the following equation [17]:

$$
\sum_{i} p_{i} x_{i}=K \times \frac{n^{2}-1}{n^{2}+2} \times \frac{M_{m o l}}{d}
$$

where $x_{i}$ is the molar percentage of the constituent element with the electric polarizability of $p_{i} ; K$ is a constant, and $M_{m o l}$ is the molar mass of the glass. Eq.(1) can also be expressed by:

$$
\sum_{i} R_{i} x_{i}=\frac{n^{2}-1}{n^{2}+2} \times V_{m o l}
$$

where $R_{i}=p_{i} / K$, is the molar refractivity and $V_{m o l}=M_{m o l} / d$ is the molar volume. The refractive index $n$ can then be calculated from the density $d$ using Eq.(3) granted the values of $R_{i}$ for each constituent elements are known.

$$
n^{2}=\frac{2 \sum_{i} R_{i} x_{i}+V_{m o l}}{V_{m o l}-\sum_{i} R_{i} x_{i}}
$$

The molar refractivity $R_{i}$ of $\mathrm{Ge}$, As and $\mathrm{S}$ elements were evaluated by the least-squares fitting method using the measured $n$ and $d$ of the investigated glasses and Eq.(2). The optimal average values of molar refractivity for each elements are $R_{G e}=10.07, R_{A s}=11.78$, and $R_{S}=7.82 \mathrm{~cm}^{3} / \mathrm{mol}$ for glasses in the Ge-As-S system. In 
order to assess the divergence of Eq.(3) for the determination of $n$ using these molar refractivity values, the calculated refracted index values $n_{c a l}$ of each glass were compiled and compared with the measured values $n_{\text {mea }}$ as shown in Table 1 . The correlation plot between $n_{\text {mea }}$ and $n_{\text {cal }}$ shown in Fig. 3 indicates an excellent match and the deviation of $n_{\text {cal }}$ from $n_{\text {mea }}$ is below $1 \%$. It is therefore expected that the refractive index of any glass composition in the Ge-As-S system can be predicted using Eq.(3) from its density. It is worth mentioning that the molar refractivity of $\mathrm{Ge}$, As and $\mathrm{S}$ were determined empirically for $n$ values at $6 \mu \mathrm{m}$, hence the $n_{\text {cal }}$ values determined from Eq.(3) should be only valid at that wavelength. This is important because the refractive index dispersion of sulfide glasses is significant $[10,18]$.

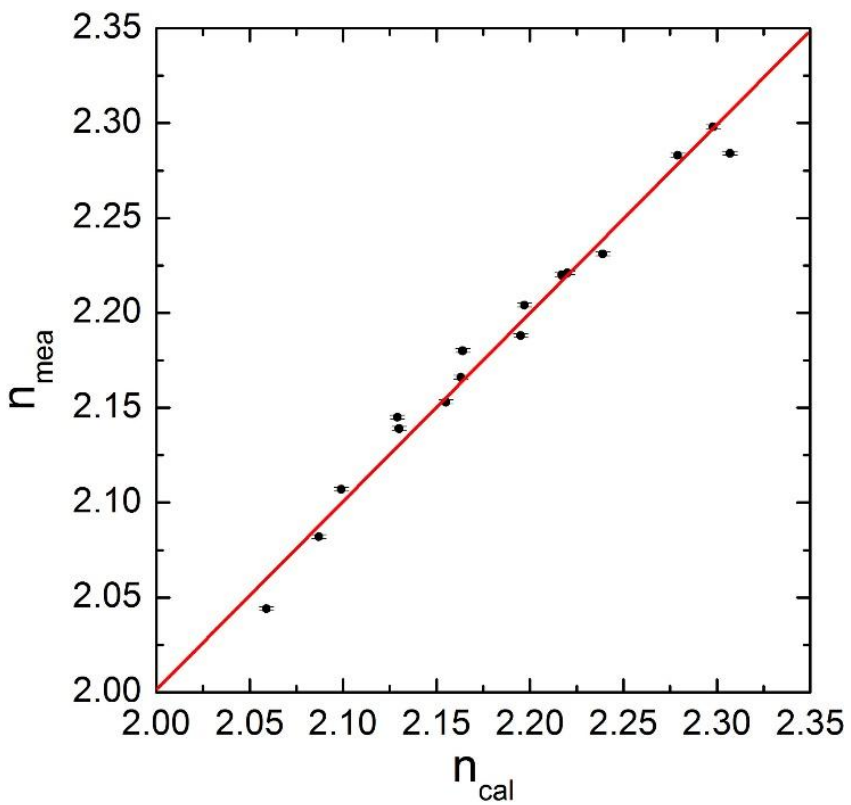

Fig.3. Correlation between the measure $n$ and the calculated $n$ using Eq.(3).

\subsection{Optical bandgap}

$E_{g}$ of a glass is usually obtained by conducting a Tauc plot [19] on the absorption spectrum measured using a spectrophotometer. According to Tauc, electronic transitions from delocalized states in the valence band to delocalized states of the 
conduction bands lead to the optical absorption behavior in the region $\alpha>10^{4} \mathrm{~cm}^{-1}$ ( $\alpha$ is the absorption coefficient). To conduct a valid Tauc plot, the values of $\alpha$ as low as $\sim 10^{4} \mathrm{~cm}^{-1}$ are required. The value of $E_{g}$ is then obtained from extrapolation of the $(\alpha h v)^{1 / 2}$ vs $h v$ plot where $h v$ is the photon energy. However, a number of amorphous semiconductors do not follow a quadratic energy dependence [20] and a more common approach is to define $E_{g}$ as the photon energy for which $\alpha$ reach some fixed value in the Tauc region, usually $10^{4} \mathrm{~cm}^{-1}[19,20]$ or $10^{3} \mathrm{~cm}^{-1}[21]$. For a $1 \mathrm{~mm}$-thick bulk glass, the detection limit of a spectrophotometer is typically $\alpha<100 \mathrm{~cm}^{-1}$. To reach the Tauc plot region, the sample thickness used for the measurement has to be less than $10 \mu \mathrm{m}$. Because of this, useful data are usually collected on thin films. However, it is difficult to prepare chalcogenide films (e.g. Ge-As-S, Ge-Sb-S, Ge-Sb-Se) with accurate nominal compositions, and therefore a number of researchers used thin bulk samples [22-24] for the measurements. The $E_{g}$ determined this way turned out to be smaller than those obtained on corresponding films. It is not surprising because the Tauc linear extrapolation carried out to obtain $E_{g}$ on bulk samples were not really conducted in the Tauc plot region, but in a region with much smaller $\alpha$.

DRS provide another approach to obtain $\mathrm{E}_{\mathrm{g}}$ of a glass. Based on DRS of glass powders, the Kubelka-Munk function $F(R)[25,26]$ can be calculated according to Eq.

$$
F(R)=\frac{(1-R)^{2}}{2 R}
$$

where $\mathrm{R}$ is the reflectance in acquired DRS. The $F(R)$ is proportional to the absorption coefficient of the glass $\alpha[25,26]$, hence $\mathrm{E}_{\mathrm{g}}$ could be determined based on calculated $F(R)$. However, the effective absorption length is unknown in a reflection experiment so that the absolute value of $\alpha$ cannot be obtained. Instead we define $E_{g}$ as the photon 
energy for which $F(R)$ reach some fixed value in the Tauc region determined by calibrating the method with a standard glass with similar electric band structure and known value of $E_{g}$. In this experiment we calibrated the absorbance using DRS of $\mathrm{As}_{2} \mathrm{~S}_{3}$ glass powders with a size of $\sim 15 \mu \mathrm{m}$. It is well known that $\mathrm{As}_{2} \mathrm{~S}_{3}$ glass has an $E_{g}$ of $\sim 2.40 \mathrm{eV}[27,28]$. As an example, Fig.4a presents a diffuse reflectance spectrum of $\mathrm{As}_{2} \mathrm{~S}_{3}$ fine glass powders with a size of $\sim 15 \mu \mathrm{m}$, and Fig.4b displays the absorption spectra derived from the DRS. For comparison, transmission or absorption spectra of $\mathrm{As}_{2} \mathrm{~S}_{3}$ bulk glasses with different thickness are also included in the figures. Figures $4 \mathrm{a}$ and $4 \mathrm{~b}$ indicate that the transmission or absorption spectra of bulk glasses get cut-off far above the wavelength $(\sim 516 \mathrm{~nm})$ corresponding to the $E_{g}$, making it impossible to collect absorption data in the $10^{4} \mathrm{~cm}^{-1}$ range required for $E_{g}$ determination. In comparison, the DRS or derived absorption spectra of powders provide measurable data around $516 \mathrm{~nm}$, making it possible to define a fixed DRS absorption value for the determination of $E_{g}$ from these data. In order to determine this fixed DRS absorption value we used the known $E_{g}$ value of our $\mathrm{As}_{2} \mathrm{~S}_{3}$ standard glass. The value of $E_{g}(2.40$ $\mathrm{eV}$ ) corresponds to a DRS absorbance of $\sim 3.93$ (Fig.4b). If all DRS are collected in the same conditions (e.g. same size of glass powders, same testing condition), the same absorbance value can yield a systematic value of $E_{g}$. Using the same DRS absorbance value of $3.93, E_{g}$ of the Ge-As-S glasses (see table 1) were determined based on DRS of powders measured in the same condition. 

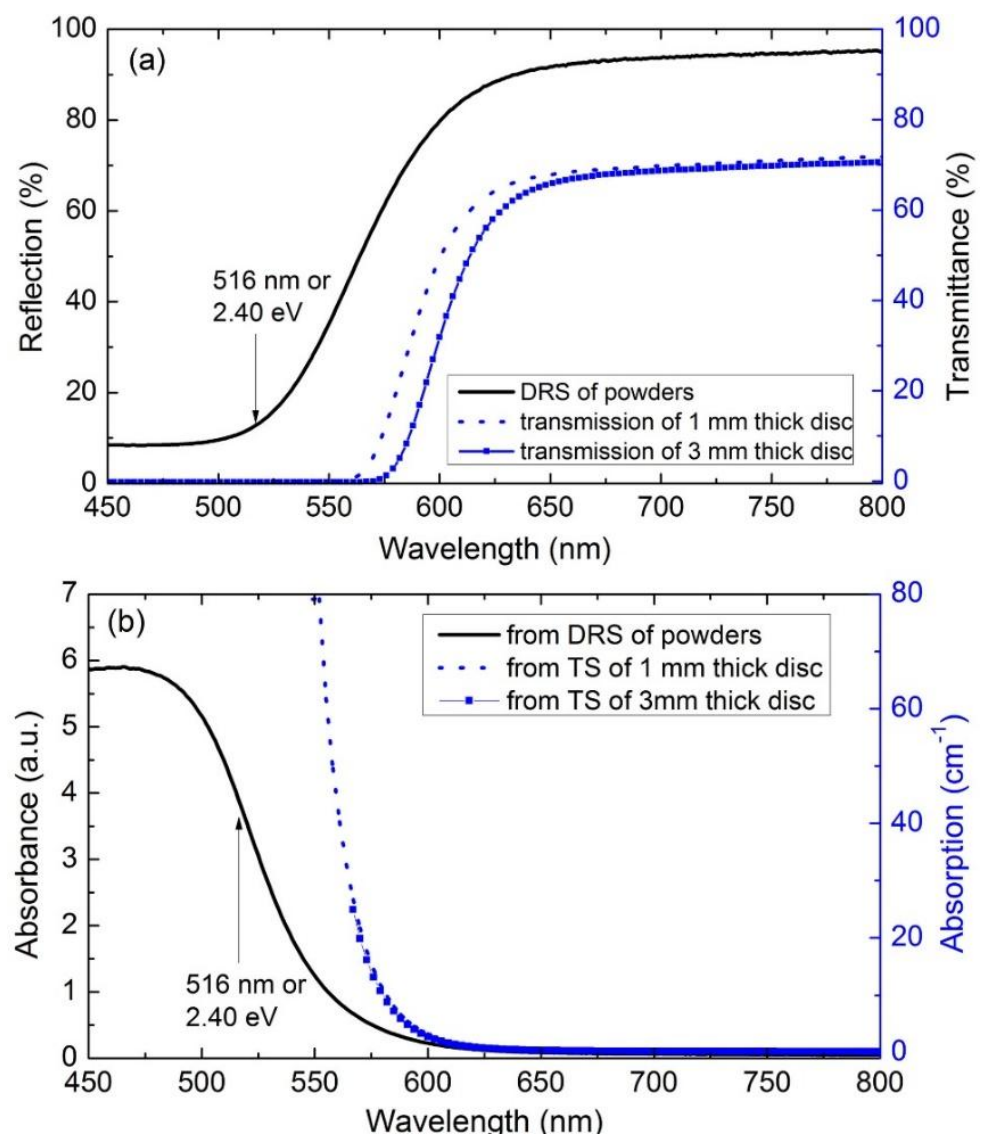

Fig.4 (a) Diffuse reflectance spectrum of $\mathrm{As}_{2} \mathrm{~S}_{3}$ glass powders with a size of $\sim 15 \mu \mathrm{m}$, and transmission spectra (TS) of $\mathrm{As}_{2} \mathrm{~S}_{3}$ glass discs; (b) Absorption spectra of $\mathrm{As}_{2} \mathrm{~S}_{3}$ glasses derived from corresponding data in (a).

$E_{g}$ of a glass depends on the average electron affinity of anions, the average bonding energy and the average polarization energy of ions in the glass [17, 29]. Although some investigations on chalcogenide glasses $[19,28]$ indicated that a glass with smaller $E_{g}$ was more likely to show a higher $n$, especially $n$ increased with decreasing $E_{g}$ when a chalcogenide glass was subjected to photodarkening, we did not find clear correlation between $n$ and $E_{g}$ in the Ge-As-S glasses. It is not surprising because the influencing factors of $n$ and $E_{g}$ are significantly different, although both of them are related to the electric polarizability of constituent elements in the glasses.

Instead we find a broad correlation between the bandgap and the sulfur content as depicted in Fig. 5. This is consistent with the expected dependence on the optical 
bandgap value on the molar bond energy [19]. Indeed the corresponding bond energies are $\mathrm{E}_{\mathrm{S}-\mathrm{S}}=280 \mathrm{~kJ} / \mathrm{mol}, \mathrm{E}_{\mathrm{Ge}-\mathrm{S}}=265 \mathrm{~kJ} / \mathrm{mol}, \mathrm{E}_{\mathrm{As}-\mathrm{S}}=260 \mathrm{~kJ} / \mathrm{mol}, \mathrm{E}_{\mathrm{As}-\mathrm{As}}=200 \mathrm{~kJ} / \mathrm{mol}$ and $\mathrm{E}_{\mathrm{Ge}-\mathrm{Ge}}=185 \mathrm{~kJ} / \mathrm{mol}$. It is therefore expected that sulfur rich glass will have higher molar bond energies while sulfur-deficient glasses containing homopolar metal bonds will have lower molar bond energies and consequently lower bandgap values. This is also consistent with the fact that Ge-As-S glasses exhibit chemical order so that homopolar metal bonds only appear in sulfur deficient glasses [30]. In addition, sulfur has a notably higher electron affinity $(200 \mathrm{~kJ} / \mathrm{mol})$ than $\mathrm{Ge}(116 \mathrm{~kJ} / \mathrm{mol})$ and As $(78$ $\mathrm{kJ} / \mathrm{mol}$ ) which also contributes to the increase in bandgap energy with increasing sulfur content.

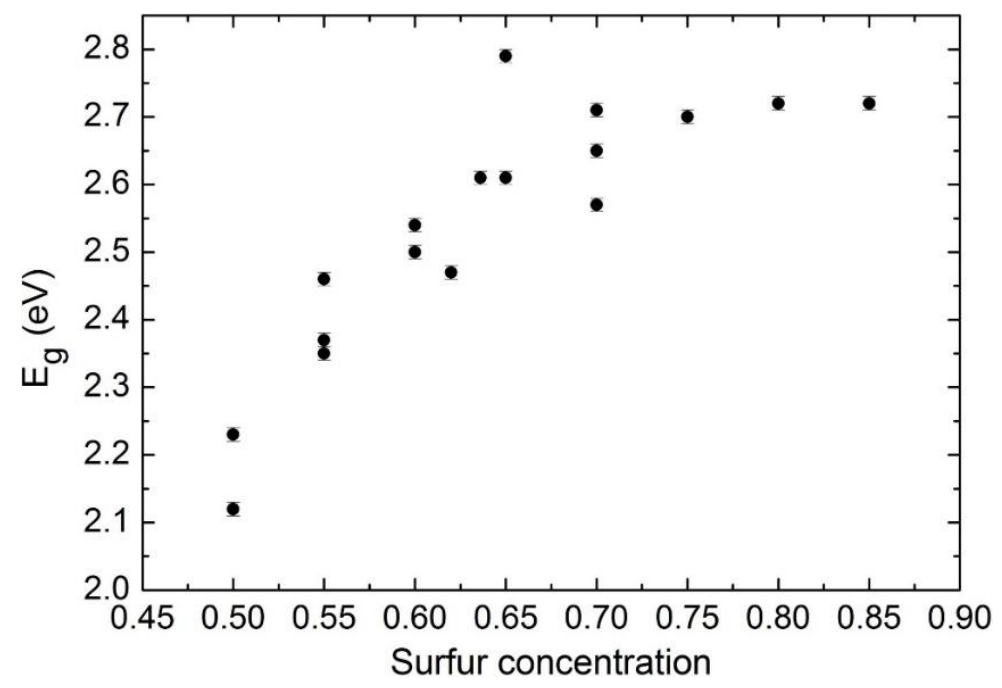

Fig.5 Correlation between bandgap $\mathrm{E}_{\mathrm{g}}$ and sulfur content in Ge-As-S glasses.

\section{Conclusion}

It is shown that the density of Ge-As-S glasses is linearly correlated with the sulfur content but is not well correlated to the $M C N$ or the refractive index $n$. Instead a relation based on the molar reflectivity of Ge, As and $\mathrm{S}$ and the glass density is shown to predict the refractive index with an error below $1 \%$. The estimated values of molar reflectivity for Ge, As and $\mathrm{S}$ elements are 10.07, 11.78, and $7.82 \mathrm{~cm}^{3} / \mathrm{mol}$, 
respectively. It is also shown that a reasonable optical bandgap $\mathrm{E}_{\mathrm{g}}$ of a glass could be determined from DRS of the glass powders. The $\mathrm{E}_{\mathrm{g}}$ of Ge-As-S glasses is found to decrease with decreasing sulfur content. Following these findings, refractive index, density and optical bandgap of a glass in Ge-As-S system could be tailored intentionally.

\section{Acknowledgements}

This work was supported by the National Natural Science Foundation of China (61205207, 61575086, 61405080, 51303072), the Priority Academic Program Development of Jiangsu Higher Education Institutions, and Jiangsu Collaborative Innovation Centre of Advanced Laser Technology and Emerging Industry. This work was also supported by NSF-ECCS under Grant \#1201865.

\section{References}

[1] X. Zhang, Y. Guimond and Y. Bellec, "Production of complex chalcogenide glass optics by molding for thermal Imaging," J. Non-Cryst. Solids 326-327 (2003) 519-523.

[2] D. Cha, H. Kim, Y. Hwang, J. Jeong, and J. Kim, "Fabrication of molded chalcogenide-glass lens for thermal imaging applications," Appl. Opt. 51 (2012) 5649-5656.

[3] G. E. Snopatin, V. S. Shiryaev, V. G. Plotnichenko, E. M. Dianov, and M. F. Churbanov, "High-purity chalcogenide glasses for fiber optics", Inorg Mater. 45 (2009) 1439-1460.

[4] J. Sanghera and D. Gibson, "Optical properties of chalcogenide glasses and fibers," in Chalcogenide glasses: Preparation, properties and applications, pp.113-138, edited by Jean-Luc Adam and Xianghua Zhang, Woodhead Publishing, Oxford, 2014.

[5] P. Lucas, M. R. Riley, C. Boussard-Pledel, and B. Bureau, "Advances in Chalcogenide Fiber EvanescentWave Biochemical Sensing," Anal. Biochem. 351 (2006) 1-10.

[6] J. Charrier, M. L. Brandily, H. Lhermite, K. Michel, B. Bureau, F. Verger, and V. Nazabal, "Evanescent wave optical micro-sensor based on chalcogenide glass," Sens. Actuators 
B-Chem. 173 (2012) 468-476.

[7] P. Ma, D. Choi, Y. Yu, X. Gai, Z. Yang, S. Debbarma, S. Madden and B. Luther-Davies, "Low-loss chalcogenide waveguides for chemical sensing in the mid-infrared," Opt. Express, $21(2013)$ 29927-29937.

[8] B. J. Eggleton, B. Luther-Davies, and K. Richardson, "Chalcogenide photonics", Nat Photonics 5 (2011) 141-148.

[9] C. R. Petersen, U. Møller, I. Kubat, B. Zhou, S. Dupont, J. Ramsay, T. Benson, S. Sujecki, N. Abdel-Moneim, Z. Tang, D. Furniss, A. Seddon, and O. Bang, "Mid-infrared supercontinuum covering the $1.4-13.3 \mu \mathrm{m}$ molecular fingerprint region using ultra-high NA chalcogenide step-index fibre," Nat Photonics 8 (2014) 830-834.

[10] B. Zhang, W. Guo, Y. Yu, C. Zhai, S. Qi, A. Yang, L. Li, Z. Yang, R. Wang, D. Tang, G. Tao and B. Luther-Davies, "Low loss, high NA chalcogenide glass fibers for broadband mid-infrared supercontinuum generation,” J. Am. Ceram. Soc. 98 (2015) 1389-1392.

[11] M. F. Thorpe, "Continuous deformations in random networks," J. Non-Cryst. Solids 57 (1983) 355-370 .

[12] M. Stabl, and L.Tichy," On the photo-darkening in some Ge-As-S glasses," J. Opt. Adv. Mater. 6 (2004) 781-786.

[13] M. Kincl, and L. Tichy, "Some physical properties of $\mathrm{Ge}_{x} \mathrm{As}_{\mathrm{x}} \mathrm{S}_{1-2 \mathrm{x}}$ glasses," Mater. Chem. Phys. 103 (2007) 78-88.

[14] Y. Yu, B. Zhang, X. Gai, C. Zhai, S. Qi, W. Guo, Z. Yang, R. Wang, D. Choi, S. Madden, and B. Luther-Davies,"1.8-10 $\mu \mathrm{m}$ mid-infrared supercontinuum generated in a Step-index chalcogenide fiber using low peak pump power," Opt. Lett. 40 (2015) 1081-1084.

[15] H. Dantanarayana, N. Abdel-Moneim, Z. Tang, L. Sojka, S. Sujecki, D. Furniss, A. Seddon, I. Kubat, O. Bang, and T. Benson, "Refractive index dispersion of chalcogenide glasses for ultra-high numerical-aperture fiber for mid-infrared supercontinuum generation," Opt. 
Express, 4 (2014) 1444-1455.

[16] S. Mamedov, D.G. Georgiev, T. Qu and P. Boolchand,"Evidence for nanoscale phase separation of stressed-rigid glasses," J. Phys.: Condens. Matter. 15 (2003) S2397-S2411.

[17] M. L. Cui, Glass Technology, pp. 140-153. Light Industry Press, Beijing, 1987.

[18] E. Guillevica, X. Zhanga, T. Paina, L. Calveza, J. Adama, J. Lucas, M. Guilloux-Viryb, S. Ollivierb, and G. Gadretc,"Optimization of chalcogenide glass in the As-Se-S system for automotive applications," Opt. Mater. 31 (2009) 1688-1692.

[19] A. Feltz, Amorphous Inorganic Materials and Glasses, pp.319-384. VCH, Weinheim, 1993.

[20] S. R. Elliott, Physics of amorphous materials, p.236, Longman, London, 1983.

[21] R. A. Street, "Luminescence in amorphous semiconductors," Adv. Phys. 25 (1976) 397-453.

[22] M. Munzar, and L. Tichy,"Far-infrared spectra and bonding arrangement in Ge-As-S-Se glasses," J. Phys. Chem. Solids 61 (2000) 1647-1652.

[23] Y. Xu, G. Yang, W. Wang, H. Zeng, X. Zhang, and G. Chen, "Formation and properties of the novel $\mathrm{GeSe}_{2}-\mathrm{In}_{2} \mathrm{Se}_{3}$-CsI chalcohalide glasses," J. Am. Ceram. Soc. 91 (2007) 902-905.

[24] T. Wang, X. Gai, W. Wei, R. Wang, Z. Yang, X. Shen, S. Madden, and B. Luther-Davies, "Systematic z-scan measurements of the third order nonlinearity of chalcogenide glasses," Opt. Mater. Express 4 (2014) 1011-1022.

[25] J. Torrent, and V. Barron, "diffuse reflectance spectroscopy," in book Methods of Soil Analysis: Part 5-Mineralogical Methods, pp. 367-385, edited by A. L. Ulery and L. R. Drees, Soil Science Society of America, Madison, 2008.

[26] B. Karvaly, and I. Hevesi, "Diffuse reflectance spectra of vanadium pentoxide powder," Z. Naturforsch. A 26 (1971) 245-249.

[27] V. M. Rubish, E.B. Gera, M. M. Pop, V.M. Maryan, S. O. Kostyukevych, N. L. Moskalenko, D. G. Semak, K. V. Kostyukevych, A. A. Kryuchin, and V. V. Petrov, "Photo-thermoinduced changes of transmission spectra of $\mathrm{As}_{40-\mathrm{x}} \mathrm{Sb}_{\mathrm{x}} \mathrm{S}_{60}$ amorphous layers," Semicond. Phys. Quantum 
Electron. Optoelectron. 12 (2009) 251-254.

[28] K. Tanaka, "Photo-induced phenomena in chalcogenide glasses," in Chalcogenide glasses: Preparation, properties and applications, pp.139-168, edited by Jean-Luc Adam and Xianghua Zhang, Woodhead Publishing, Oxford, 2014.

[29] Z. Yang, L. Luo, and W. Chen, "Red color $\mathrm{GeSe}_{2}$-based chalcohalide glasses for infrared optics," J. Am. Ceram. Soc. 89 (2006) 2327-2329.

[30] Y. Yang, B. Zhang, A. Yang, Z. Yang, and P. Lucas, "Structural Origin of Fragility in Ge-As-S Glasses Investigated by Calorimetry and Raman Spectroscopy," J. Phys. Chem. B 119 (2015) 5096-5101. 